\title{
Effect of second time Xenopus egg extract treatment on colony formation and cloned blastocyst formation in pig
}

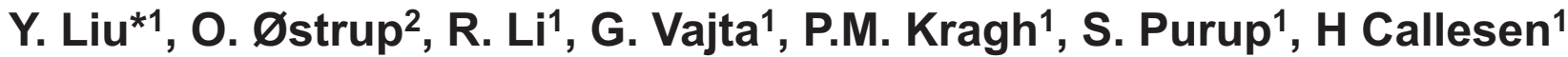 \\ Dpt. of Animal Science, Science and Technology, Aarhus University, Tjele-8830, Denmark ${ }^{1}$ \\ Dpt. of Anim. Vet. Basic Sci. KU-LIFE, University of Copenhagen, Frederiksberg-1870, Denmark ${ }^{2}$
}

\section{Introduction and Aim}

* Extract from Xenopus eggs can induce reprogramming in somatic cells.

* In our previous study, cell colony formation was induced during culture of porcine fetal fibroblasts after a single treatment with Xenopus egg extract and culture for several passages, and using these long-term cultured cells for cloning increased the resulting blastocyst rate (Liu et al. 2011 Reprod Fertil Dev 23:130).

* However, both colony number and cloned blastocyst rate decreased using cells after Passage 15, and no colonies formed when cells were used after Passage 18.

* Aim of this study: to investigate the effect of a second extract treatment on (i) colony formation on porcine fetal fibroblasts and on (ii) blastocyst formation after use of these cells for cloning.

\section{Materials and Methods}

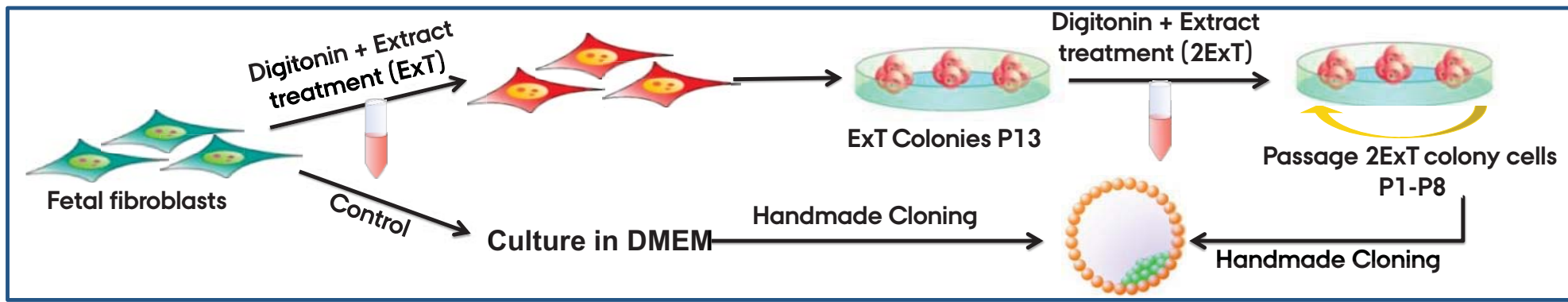

\section{Results}

Colony formation during culture of porcine fibroblasts extract-treated once (ExT) or twice (2ExT)
Blastocyst rate of cloned embryos produced with ExT and 2ExT colony cells or control cells

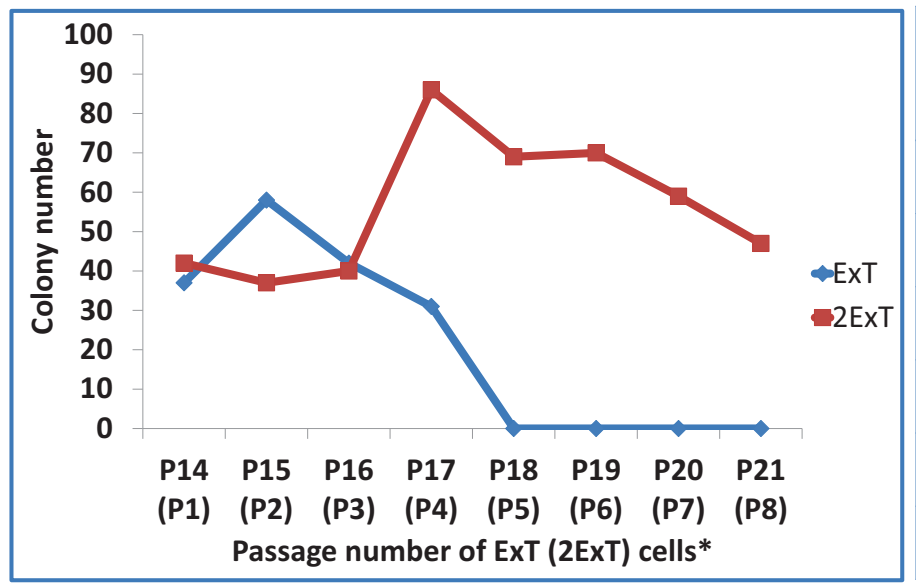

* 2ExT P1 = ExT P14.
Group

(ExT)

Blastocyst \%

(No.) ${ }^{1}$

P14

Control

P16

Control

P19

Control

1: mean $\pm S D ; a, b$ : significant difference, $P<0.05$

Blastocyst \%

(No.) ${ }^{1}$

(2ExT)

\begin{tabular}{l|l} 
P1 & $70 \pm 6 \%(82)^{a}$
\end{tabular}

$65 \pm 7 \%(170)^{\mathrm{a}} \quad \mathrm{P} 1$

$62 \pm 9 \%(78)^{\mathrm{a}}$

$57 \pm 5 \%(168)^{a}$

Control

P3

$74 \pm 11 \%(60)^{\text {a }}$

$57 \pm 10 \%(85)^{\text {a }}$

Control

$50 \pm 14 \%(56)^{b}$

P6

$64 \pm 14 \%(101)^{a}$

Control

$45 \pm 10 \%(96)^{b}$

\section{Conclusion and Discussion}

A second extract treatment can induce colony formation and increase cloned blastocyst rates, indicating that this repeated extract treatment could again activate the extract-treated cells to an activity level similar to those achieved after the first extract treatment. 